\title{
The Power of Embedded Critics
}

\author{
Brian W. Powers, $A B^{7}$, Christine K. Cassel, $M D^{2}$, and Sachin H. Jain, $M D, M B A^{7,3,4}$ \\ ${ }^{1}$ Harvard Medical School, Boston, MA, USA; ${ }^{2}$ National Quality Forum, Washington, DC, USA; ${ }^{3}$ Boston-VA Medical Center, Boston, MA, USA; \\ ${ }^{4}$ Merck and Co., Inc., Boston, MA, USA.
}

J Gen Intern Med 29(7):981-2

DOI: $10.1007 / \mathrm{s} 11606-014-2825-\mathrm{x}$

() Society of General Internal Medicine 2014

$\mathrm{H}$ ealth care is in a period of fundamental transformation, with reform activities coming from every sector: politicians and government officials; consumers; industry; payers; and the health professions. What is the role of physicians in shaping this transformation?

Arguments for physician engagement typically follow a narrow dialogue. Within our profession, physicians champion self-regulation over external control. Beliefs that physicians are responsible for cost and quality challenges lead many outside of the profession to call for physician leadership. These dialogues obscure a more fundamental rationale for the importance of physician leadership - the power of embedded criticism. ${ }^{1}$

Political philosopher Michael Walzer has argued that reformers are most effective when they come from the ranks of the institutions they critique. These embedded critics derive unique insight and power from their position. They understand the common concerns and values of their institution, and can leverage this shared understanding in their critiques. Embedded critics appeal to their peers while questioning their motives and challenging the status quo. This is exquisitely powerful and constructively disruptive; the mores of their peers become the currency for their critiques.

Walzer focuses his analyses on historical social critics such as philosopher-scientist Michel Foucault and writer George Orwell, but the power of embedded criticism is manifest in our contemporary institutions. For example, calls for campaign finance reform were most successful and effective when they came from veteran legislators such as John McCain and Russell Feingold.

Understanding the paradigm of embedded criticism exposes the inherent power behind physician leadership in health care reform. Both professions and large, complex, institutions are inherently resistant to change - and our health care system is a combination of the two. As a result, external pressures to change practices are often met with resistance. However, physicians can push for change slowly

Published online March 19, 2014 from inside, remaining faithful to the traditions and morals of the profession. Through the dual roles of citizen and critic, physicians are uniquely poised to drive reform and improvement.

The career of Avedis Donabedian (1917-2000) offers a case example of the power of embedded criticism in health care. Donabedian, widely known as the father of modern quality improvement, had a tremendous and lasting impact on the medical field. His "structure-process-outcome" framework underlies almost every institutional quality improvement effort and his seven pillars of quality were the basis for the 20th century quality movement. Donabedian's writings and interviews depict a man who professed a deep reverence for, and understanding of, his profession. ${ }^{2,3}$ In the Walzerian tradition, he leveraged this understanding to appeal to the fundamental motivations and values of his peers.

Donabedian grounded his critiques with an appreciation for physicians' fundamental devotion to their patients. He explained that "the secret of quality is love...you have to love your patient, you have to love your profession...you can then work backward to monitor and improve the system." ${ }^{33}$ Rather than couching the need for improvement in terms of outcome measures and costs, Donabedian stressed that the "foundations for quality are largely moral in nature." He issued a challenge to the profession, positing that quality improvement should be an essential activity if "we take seriously our accountability to our communities." Physicians who tried to "seek refuge in the allegation that they are good clinicians but the system is wrong" drew particular ire from Donabedian; he demanded that the "system is the responsibility of physicians and hospital leadership." Donabedian appealed to physicians' love for their patients, but underscored that this love necessitated a commitment to improving quality. He was both member and critic - the Walzerian ideal.

Today, health care's most successful reformers follow this tradition. Through leadership positions in policy, professional organizations, and care delivery institutions, they successfully leverage their embedded status to drive improvement. Don Berwick roots his efforts to improve quality in our duty as healers, and paints the need to reduce disparities as a moral test. Less prolific, but equally impactful, are physician executives who drive improvement within their organizations by stressing that promoting quality is good medicine. National organizations such as Primary Care Progress and Doctors for America provide 
physicians with public-facing, coordinated opportunities for physician-led reform on specific issue areas.

The converse also holds true. Legislators, economists, and experts from other industries often struggle to have an impact on health care. Physician-reformers not only have credibility and legitimacy that outsiders sometimes lack, but they share the language and mentality needed to strike a chord with fellow physicians and build support for change.

Unfortunately, we do not sufficiently recognize and take advantage of this power - physician critics remain exceptions rather than the norm. While the willingness to acknowledge shortcomings has grown in the past couple decades, the profession remains guarded when it comes to public introspection and self-critique. A recent survey found that physicians are quick to place responsibility for health care cost control in the hands of other stakeholders, but are reluctant to assume responsibility themselves. ${ }^{5}$ Favoring this bystander approach has yielded troubling consequences: a loss of physician impact on innovation and a more dominant voice in resisting change. Not enough leadership over reform and improvement is coming from physicians and the groups that represent them. The most fundamental change to health care of the recent era, the Affordable Care Act, leaves too little room for physician leadership, focusing mostly on incentives intended to shape physician behavior.

Reform is not something that can, or should, be led solely by physicians; patients, purchasers and other health professionals are essential partners. But active physician engagement is essential to driving lasting and effective change.

A critical physician voice is important not only in motivating change from within the profession, but in shaping public perceptions of physicians and their incentives. When physicians are more honest about the imperfections and challenges of medicine, their motivations become more transparent, credible, and even noble. Embracing the role of critic and pointing out flaws in the system increases physician credibility and bolsters a public perception that physicians can be effective stewards of the health care system. Together, this can help shift the national strategies for reform away from extrinsic incentives and towards intrinsic motivation. Donabedian's critiques were powerful because they appealed to physicians' intrinsic motivations. If intrinsic motivation is going to be a major driver in reform, it must come from within the profession.
Appreciating the power of embedded criticism motivates increased physician engagement in health care system reform and transformation. These activities can take many shapes. At the individual level, physicians can seek public venues to share their critical perspective. This can be achieved through writing, or by lobbying representatives, health systems, and professional societies for more attention to these issues. Grassroots advocacy associations such as those mentioned above provide an opportunity to coordinate and consolidate these efforts, in order to reach broader audiences. Similarly, professional societies can do more to shift the tenor of their activities and messaging from defensive and guarded to proactive. This will require acknowledging flaws and inadequacies and advocating for reforms that place responsibility on physicians themselves, not just the environments within which they practice.

Within the ranks of the profession lies a reservoir of embedded critics. Harnessing this potential is essential to ensure that needed change in our system stays true to professional ideals of healing, service, and respect for patients.

Funding/Support: None.

Conflict of Interest: The authors have no potential conflicts of interest to disclose.

Disclaimers: The views expressed in this article represent the authors' views and not necessarily the views or policies of their respective affiliated institutions.

Corresponding Author: Sachin H. Jain, MD, MBA; 33 Avenue Louis Pasteur, Second Floor, Boston, MA 02115, USA (e-mail: shjain@post.harvard.edu).

\section{REFERENCES}

1. Walzer M. The Company of Crtitics. New York, NY: Basic Books; 1988.

2. Donabedian A. Avedis Donabedian: an interview. Interview by Richard Baker. Qual Health Care. 1993;2:40-46.

3. Donabedian A. A founder of quality assessment encounters a troubled system firsthand. Interview by Fitzhugh Mullan. Health Aff (Millwood). 2001:20:137-141.

4. Donabedian A. Institutional and professional responsibilities in quality assurance. Qual Assur Health Care. 1989;1:3-11.

5. Tilburt JC, Wynia MK, Sheeler RD, et al. Views of US physicians about controlling health care costs. JAMA. 2013;310:380-388. 